\title{
Numerical Analysis of Reinforced Concrete Piles under Blast Loads
}

\author{
Bhagya Jayasinghe ${ }^{1}$, Anthony T.C. Goh ${ }^{1}$, Zhiye Zhao ${ }^{1}$, Hongyuan Zhou ${ }^{2}$, Yilin Gui ${ }^{3}$ \\ ${ }^{1}$ School of Civil and Environmental Engineering, Nanyang Technological University, Singapore \\ ${ }^{2}$ Key Laboratory of Urban Security and Disaster Engineering of Ministry of Education, Beijing University of \\ Technology, China \\ ${ }^{3}$ School of Civil Engineering and Geosciences, Newcastle University, UK
}

\begin{abstract}
Pile foundations are commonly used as foundation systems for high-rise buildings and bridges. This paper uses a fully coupled three dimensional numerical modelling procedure to study the performance of pile foundations subjected to ground shocks induced by surface explosions. The comprehensive numerical model includes the pile, surrounding soil, air and the explosive. Appropriate material models are incorporated and dynamic non-linear analysis is carried out using finite element techniques. The soil in which the pile is buried could influence the blast performance of the pile. A parametric study is hence carried out to evaluate the effects of soil properties of density, friction angle, cohesion and Poisson's ratio on the blast performance of the pile. It is found that density and cohesion of soil have significant effects on the deflection of the pile under blast loading. Poisson's ratio has some effect, but effect of the soil friction angle is not very significant. The findings of this study will serve as a benchmark reference for future analysis and design of pile foundations to blast loading.
\end{abstract}

Keywords — surface explosion; pile foundation; material models; soil properties; numerical simulation

\section{INTRODUCTION}

$\mathrm{S}_{\mathrm{s}}$ ignificant and iconic buildings and other infrastructures over the world have encountered a significant increase in terrorist bomb attacks over the past two to three decades. Bomb explosions provide a sudden violent release of energy from a chemical reaction of an explosive material. In a surface explosion, a part of the energy is released as thermal energy, while the other parts are released into the air (as air blast) and into the ground (as ground shock) as rapidly expanding shock waves [1]. Blast loads are short duration dynamic loads and their typical duration is about 1000 times less than that of earthquakes. The response of a structure to blast loading could therefore be quite different from that under seismic loads. Moreover, the blast response of a structure depends on a range of parameters pertaining to the blast loading and material behaviour under rapid strain rates. Evaluating the blast response of a structure can hence be quite complex as these parameters must be included [2].

In order to design structures to withstand blast loading, it is necessary to ensure the design is suitable for the level of risk and adheres to the appropriate standards. Currently, Australian and International standards have limited provisions for designing structures for blast loading [3]. The Australian standards do not currently provide any guidance for RC pile foundations subjected to blast loading. The most relevant standard, AS 2159 (2009) [4] is limited and simply refers to the actions specified in AS/NZS 1170 (2002) [5], as well as permanent actions of pile and pile cap, ground movement, handling, installation, and any additional loads. Blast loading is not a consideration within ground movement, and although allowance of additional loads is made, a process is not provided to design specially for blast loads. Even though the actions listed in ref. [5] include liquid and earth pressures, they refer to static loads rather than dynamic loads caused by blasts. Also, this standard does not consider settlement, sliding, subsidence, liquefaction or faulting, which are possible effects of blast loading. AS 3600 (2009) [6] provides design guidelines to superstructure members of concrete structures and footings and pile caps, however piles are omitted and fire resistance is the only explosion related consideration in this standard. The content relating to blast loading in the Euro codes is similar to that of the Australian standards. However, EN 1991 Eurocode 1 (2006) [7] specially mentions accidental actions due to impacts and explosions, but this is not inclusive of external explosions.

Furthermore, many research projects on blast resistant designs have been carried out by the military services, and the relevant documents are restricted only for official use. In the open literature, much effort has been made in investigating the dynamic response and damage of structures to air propagated blast shock waves [2, 8-10]. Relatively less attention has been paid towards the blast loading on and response of foundations. Jayasinghe et al [11] developed a fully coupled method to treat the blast response of a pile foundation in saturated soil and validated the modelling techniques and the effects of end restraint of pile head and the number and spacing of piles within a group were investigated later[12]. Hao et al. [13] presented a numerical method to calculate the elastic and inelastic single pile responses to blast loads. The pile-soil system was modelled as beam-column 
elements supported by both vertical soil springs of Winkler foundation. However, this method cannot incorporate the radial and three-dimensional components of interaction. The shear stress which is acting along the side of the pile is ignored by this method. Huang et al. [14] studied the dynamic response of pile-soil-structure interaction (PSSI) system under blasting load. Solid elements were used to simulate piles, soil and pile cap, while beam elements were used to simulate columns and beams of the superstructure. They applied a velocitytime history curve of blasting seismic wave on the tip of the pile and have concluded that because of the maximum shear stress at the top of the pile, the connection of piles and pile cap are easily damaged due to maximum shear stress at the top of the pile.

The performance of foundations of structures subjected to blast loads is a critical research area, as a foundation plays an important role in the overall structural response. Pile foundations are commonly used for high-rise buildings and bridges. They transfer the large loads from the superstructure above into deeper, competent soil layers which have adequate capacity to carry these loads. It follows that if these foundations are structurally damaged due to blast loading, the superstructure becomes vulnerable to failure. It is therefore important to examine the adverse effects on foundations caused by ground shocks prior to any reconstruction or rehabilitation procedures.

Since blast experiments require the use of large amount of explosives, involving risk and danger, they are typically not feasible in civilian research. With the recent development of computer hardware technology, numerical methods have become reliable and provide a suitable means for studying the behaviour of pile foundations subjected to blast loading. The Finite Element (FE) method is a common and popular numerical method which provides a powerful tool to model the complex soil-pile interaction. It enables the study of the blast response of a pile in the time domain considering the nonlinearity of the soil medium and separation at the soil-pile interface.

This paper treats the response of a pile foundation subjected to a surface explosion using numerical simulations through the commercial software package LS-DYNA (2007) [15]. As soil properties can influence the blast response of the pile, the effects of soil properties such as soil density, Poisson's ratio, cohesion and friction angle on the blast response of pile foundation are investigated. The present study adopts the fully coupled numerical simulation approach employing nonlinear material models to represent the realistic behaviour of the soil-pile system. The Arbitrary Lagrange Euler (ALE) formulation [16] is used in the explosion, air domain and soil region near the explosion to eliminate the distortion of the mesh under high deformation. A brief description of the background on modelling and material models is presented in the following sections in this paper. A parametric study on the blast response of the pile foundation is then undertaken to capture the influence of the soil properties on the pile response. It was found that soil density and cohesion of soil have significant influence of the deflection response of the pile under blast loading. While the Poisson's ratio has some effect, the soil friction angle has minimal influence on the pile response. The findings of this paper will enhance the present knowledge base in this area and will be useful in the design of pile foundations in different soil types.

\section{METHOD OF ANALYSIS}

The focus of this study is to investigate the response of the end bearing pile foundation to the ground shock caused by a surface explosion. The present study adopts the fully coupled numerical simulation approach. Hence, the developed FE model shows the detonation of the explosive, blast wave propagation through soil and air, interaction of the blast shock wave with the pile and the pile response. The finite element modelling code LSDYNA was used for the computer simulations to meet these requirements.

A $600 \mathrm{~mm}$ circular reinforced concrete pile of $10 \mathrm{~m}$ length was considered. The reinforcement details are provided later in this section along with the details of the material model used for steel. The explosive charge used in the tests was $1000 \mathrm{~kg}$ TNT and was assumed to have a spherical shape. The explosive charge was considered to explode on the ground surface at a standoff distance of $7.5 \mathrm{~m}$. The overall model has different regions representing the soil, air, pile and explosive charge as shown in Figure 1. By making use of symmetry, only a quarter of the system was modelled.

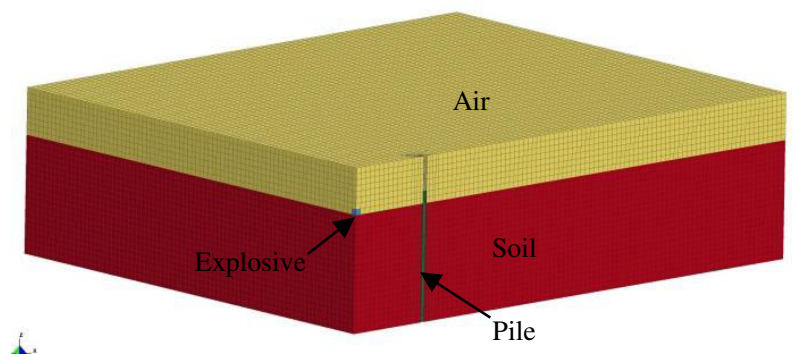

Figure 1. A quarter symmetrical FE model

Eight-node solid elements were used for the 3D explicit analysis, except for the reinforcing cage. Both the vertical reinforcements and the ties were modelled with $25 \mathrm{~mm}$ long beam elements having 2x2 Gauss integration points. The vertical reinforcements were defined using Hughes-Liu beam elements with cross integration and ties were defined using truss elements. The TNT explosive, the air and part of soil close to the explosive were modelled with ALE multi-material meshes in order to prevent element distortions that could occur under large deformations, while Lagrangian meshes were used to model the pile and the soil region away from the explosive charge.

Selecting appropriate material properties to accurately model the physical behaviour of a system is a challenge in FE modelling. In this research it was necessary to model a number of materials such as high explosive, air, soil and the RC pile made of concrete and steel. After evaluating the available soil material models in LSDYNA, it was decided to use the FHWA soil material model. This material model accounts for geometrical non linearity, material non linearity, and pore water pressure 
development. For most soil mechanics problems, it is sufficient to use the Mohr-Coulomb failure criteria. However, the standard Mohr-Coulomb surface has some deficiencies. The surface comes to a point at the intersection with the stress axis (zero shear strength). This type of singularity can cause problems in numerical computations. To avoid such an angularity, a modified Mohr-Coulomb failure criterion as described in [17] was adopted in this material model.

The explosive charge was modelled using the high explosive burn material model and the Jones-Wilkin-Lee (JWL) equation of state (EOS). The JWL equation of state defines the pressure as a function of the relative volume, $V$ and initial energy per volume, $E$, such that [15]

$P=A\left(1-\frac{\omega}{R_{1} V}\right) e^{-R_{1} V}+B\left(1-\frac{\omega}{R_{2} V}\right) e^{-R_{2} V}+\frac{\omega E}{V}$

In the above equation, $A, B, R_{1}, R_{2}$ and $\omega$ are constants pertaining to the explosive. Material parameters and JWL constants for TNT explosive are available [11] and were used in these simulations.

The null material model with a linear polynomial EOS was used to model the air. This EOS defines the pressure $P$ as a linear function of the internal energy per unit initial volume, $E$ as shown in Equation 2 below [15]

$$
P=C_{0}+C_{1} \mu+C_{2} \mu^{2}+C_{3} \mu^{3}+\left(C_{4}+C_{5} \mu+C_{6} \mu^{2}\right) E
$$

In the above equation, $C_{0}, C_{1}, C_{2}, C_{3}, C_{4}, C_{5}$, and $C_{6}$ are constant and $\mu=\frac{\rho}{\rho_{0}}-1$ where $\frac{\rho}{\rho_{0}}$ is the ratio of current density to initial density. Material parameters and EOS constants for air are available [11] and were used in these simulations.

The various materials models available in LS-DYNA to represent concrete were considered and the material model Concrete_Damage_REL3 selected for this research. This model is a plasticity-based model and has three shear failure surfaces. It includes damage and strain rate effects [18]. Earlier research reported in the literature has indicated that the material concrete_damage_rel3 model can successfully incorporate non-linear concrete properties [10, 19]. It has the advantage that only two parameters, namely the unconfined compressive strength and density of concrete are required in the calibration process. This concrete material model uses three failure surfaces; namely an initial yield surface, a maximum failure surface and a residual surface and considers all three stress invariants [18]. It can hence effectively simulate tri-axial state of stress conditions. In order to account for the increase in strengths under high strain rates, a coefficient called the dynamic increased factor (DIF) is employed in this analysis. The dynamic increase factor is the ratio of the strength at a point of interest on the stress strain curve under high strain rate dynamic loading to the strength at the corresponding strain under static loading. The expressions proposed by [20] are utilized for this purpose.

Pile reinforcement is normally required to resist the bending and tensile stresses, but may be used to carry a portion of the compression load. A total of sixteen 20 $\mathrm{mm}$ diameter bars were used as the pile vertical reinforcement in this study. $10 \mathrm{~mm}$ diameter steel bars were used for the transverse reinforcement. Transverse reinforcement ratio of $0.24 \%$ was provided in the pile at spacing of $200 \mathrm{~mm}$. Reinforcements were modelled as elastic perfectly-plastic materials using the plastic kinematic model available in the LS-DYNA. Kinematic hardening with strain rate effects was implemented for the reinforcement.

The erosion algorithm was used to simulate the crushing of concrete in the finite element model. When the material response in an element reaches a certain critical value, the element is immediately deleted. This provides an efficient means to imitate concrete spalling phenomena and produce graphical plots which are more realistic representations of the actual events. There may be a variety of criteria governing the material erosion. In this study, the concrete elements in the pile were allowed to erode when the principle tensile strain reached 0.01 [21].

The bottom of the FE model mesh was constrained in all directions to represent the bed rock. To form the symmetry in the FE model, the translational displacements of nodes normal to the symmetry planes were constrained and nodes along the interfaces between the air and soil were merged. Fixed boundary conditions were considered at the top and bottom of the pile.

The Automatic_Surface_to_Surface contact option in LS-DYNA assumes contact at the surface and enables transfer of stresses between the solid materials. In the present research the interaction between the pile and surrounding soil was modelled by specifying this option. The contact nonlinearity was established by assigning a value of 30 for the viscous damping coefficient. In addition, static and dynamic friction coefficients of 0.5 and 0.3 respectively were introduced to simulate the frictional forces that are transmitted across the contact interface. Thus, this contact method was used at the soilpile interface to allow for separation in tension and ensured compatibility in compression.

A proper coupling mechanism needs to be used to achieve good interaction between concrete and reinforcement elements. There are various ways to achieve coupling in LS-DYNA such as merging the reinforcing beam elements with solid concrete elements in the form of shared nodes, which most researchers have used in their studies. The Constrained _Lagrange_in_Solid option in LS-DYNA was used to couple concrete solid elements with the reinforcing cage in this research. This method when used with the fluidstructure coupling mechanism of CTYPE $=2$, couples concrete with reinforcement in an efficient manner and it removes the problem of having to align the beam nodes to the solid element nodes.

\section{ANALYSIS CASES}

Then main purpose of the parametric study is to investigate the blast performance of the pile foundation under changes in soil properties. Four different analyses cases were considered, and the details of which are described below and listed in Table 1. The different 
values for soil density were considered to understand the blast response of pile embedded in loose dry sand to stiff clay soil. The values of friction angle and cohesion were considered for different soil types and the values of Poisson's ratio were varied to understand the blast response of piles in dry soil and saturated soil.

Case 1: Soil cohesion varies from 0 to $100 \mathrm{kPa}$ whereas friction angle, Poisson's ratio and soil density are kept unchanged at $20^{\circ}, 0.4$ and $1960 \mathrm{~kg} / \mathrm{m}^{3}$, respectively.

Case 2: For soil cohesion $50 \mathrm{kPa}$, the friction angle is varied from $20^{\circ}$ to $45^{\circ}$ while Poisson's ratio and soil density are kept unchanged at 0.4 and $1960 \mathrm{~kg} / \mathrm{m}^{3}$, respectively.

Case 3: Soil cohesion, friction angle and density are kept unchanged at $50 \mathrm{kPa}, 40^{\circ}$ and $1960 \mathrm{~kg} / \mathrm{m}^{3}$, respectively, while Poisson's ratio is varied across 0.2 , $0.25,0.3,0.35$ and 0.4 .

Case 4: Soil density is varied from 1250 to $1960 \mathrm{~kg} / \mathrm{m}^{3}$ whereas cohesion, friction angle and Poisson's ratio are kept unchanged at $50 \mathrm{kPa}, 40^{\circ}$ and 0.4 , respectively.

Table 1.Analysis cases

\begin{tabular}{|c|c|c|c|c|c|}
\hline \multirow[b]{2}{*}{ Case } & \multirow[b]{2}{*}{$\begin{array}{c}\text { Varied } \\
\text { parameter }\end{array}$} & \multicolumn{4}{|c|}{ Soil properties } \\
\hline & & $\begin{array}{c}\text { density, } \\
\rho \\
\left(\mathrm{kg} / \mathrm{m}^{3}\right)\end{array}$ & $\begin{array}{c}\text { friction } \\
\text { angle } \\
\left(\varphi^{0}\right)\end{array}$ & $\begin{array}{c}\text { cohesion, } \\
c(\mathrm{kPa})\end{array}$ & $\begin{array}{l}\text { Poisson's } \\
\text { ratio, } v\end{array}$ \\
\hline \multirow[t]{5}{*}{1} & cohesion & 1960 & 20 & 0 & 0.4 \\
\hline & & & & 20 & \\
\hline & & & & 50 & \\
\hline & & & & 75 & \\
\hline & & & & 100 & \\
\hline \multirow[t]{5}{*}{2} & friction & 1960 & 20 & 50 & 0.4 \\
\hline & & & 30 & & \\
\hline & & & 35 & & \\
\hline & & & 40 & & \\
\hline & & & 45 & & \\
\hline \multirow[t]{5}{*}{3} & Poisson's & 1960 & 40 & 50 & 0.2 \\
\hline & & & & & 0.25 \\
\hline & & & & & 0.3 \\
\hline & & & & & 0.35 \\
\hline & & & & & 0.4 \\
\hline \multirow[t]{4}{*}{4} & density & 1250 & 40 & 50 & 0.4 \\
\hline & & 1500 & & & \\
\hline & & 1750 & & & \\
\hline & & 1960 & & & \\
\hline
\end{tabular}

\section{RESULTS AND DISCUSSION}

In this section results for the blast response of the pile foundation in terms of its horizontal displacement, which is an important response parameter, are presented. The influence of soil properties in terms of its cohesion, friction angle, Poison's ratio and density on the maximum and residual horizontal displacements of the pile are evaluated and discussed.

Figure 2 shows the time histories of the horizontal displacements of the pile obtained at 7 monitoring points on the pile at different heights from the pile bottom: 0.5 $\mathrm{m}$ (point A), $2 \mathrm{~m}$ (point B), $4 \mathrm{~m}$ (point C), $5 \mathrm{~m}$ (point D), $6 \mathrm{~m}$ (point $\mathrm{E}$ ), $8 \mathrm{~m}$ (point $\mathrm{F}$ ) and $9.25 \mathrm{~m}$ (point $\mathrm{G}$ ) for analysis case 1 with the cohesion of $100 \mathrm{kPa}$. This Figure demonstrates that the pile has residual deflections along its height. These residual deflections indicate the occurrence of plastic deformation of the pile, which means that the pile has suffered permanent deformation under the blast event.

Figure 3 compares the maximum horizontal displacements and the residual horizontal displacements of that pile along its height. The maximum pile displacements of $26 \mathrm{~mm}$ and maximum residual displacements of $16.4 \mathrm{~mm}$ occur at the monitoring point E located $6 \mathrm{~m}$ above the pile bottom. This could mean that point $E$ is a potential failure region of this pile under the blast loading.

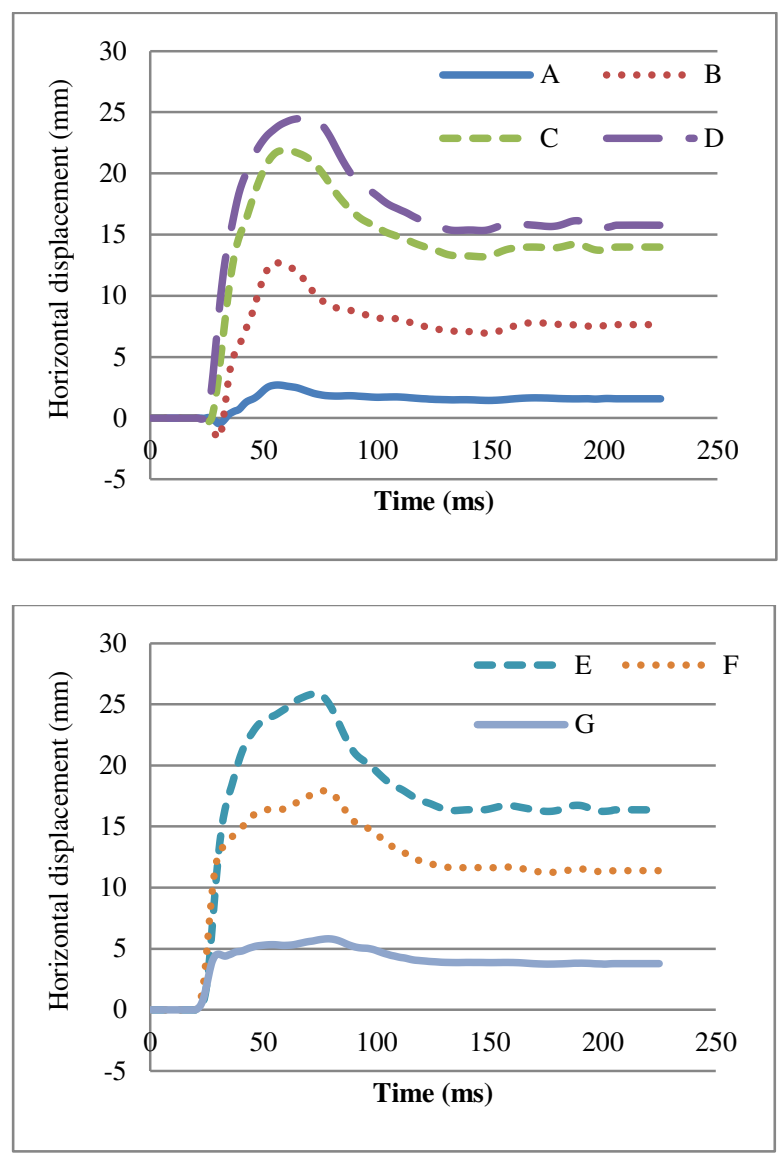

Figure 2. Horizontal pile displacement vs. time at the monitoring points for case 1 with $\mathrm{c}=100 \mathrm{kPa}$

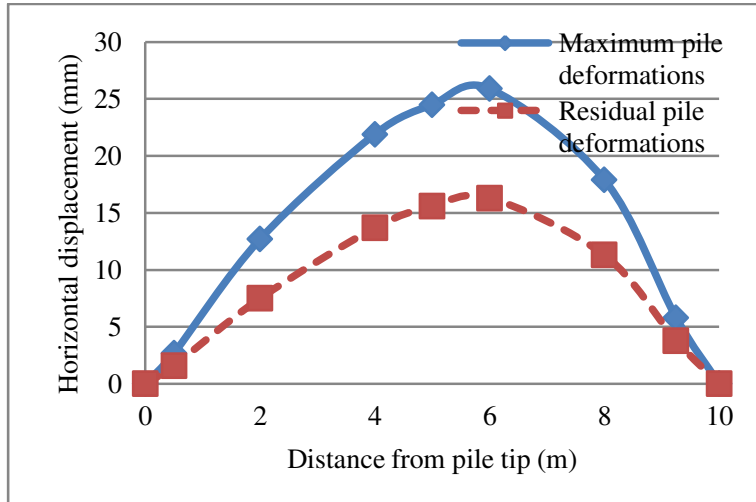

Figure 3. Maximum and residual horizontal deformations of pile for case 1 with $\mathrm{c}=100 \mathrm{kPa}$

From the analyses, both peak and residual deflections of the pile were obtained for the soil cohesion of 0 to 100 
$\mathrm{kPa}$, and Figure 4 shows the maximum and residual deflections of the pile at the mid-height (point D located $5 \mathrm{~m}$ above the pile bottom) of the pile against the soil cohesion. As soil cohesion increase from 0 to $100 \mathrm{kPa}$, the maximum horizontal deflection of the pile decreases approximately $41 \%$ whereas its residual horizontal deflection decreases approximately 40\%. From this study, it can be concluded that the soil cohesion has a significant effect on pile deflections which decrease with increase in soil cohesion.

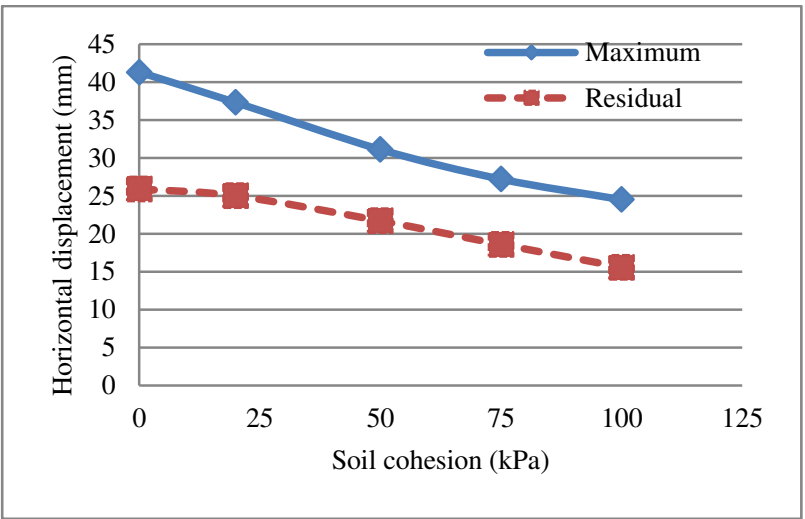

Figure 4. Pile displacements versus soil cohesion

Figure 5 depicts the maximum and residual deflections of the pile at its mid-height against the soil friction angle. It can be observed from this Figure that the maximum pile deflection at the mid-height of the pile gradually decreases as the soil friction angle increases. It initially decreases linearly from $31 \mathrm{~mm}$ to $27 \mathrm{~mm}$ with increase of soil friction angle from $20^{\circ}$ to $35^{\circ}$ and then linearly deceases with a much reduced slope with increase of friction angle from $35^{\circ}$ to $45^{\circ}$. However, from Figure 5 also it can be seen clearly that the residual horizontal deflection of the pile at its mid-height has minimal variation with changes in the soil friction angle.

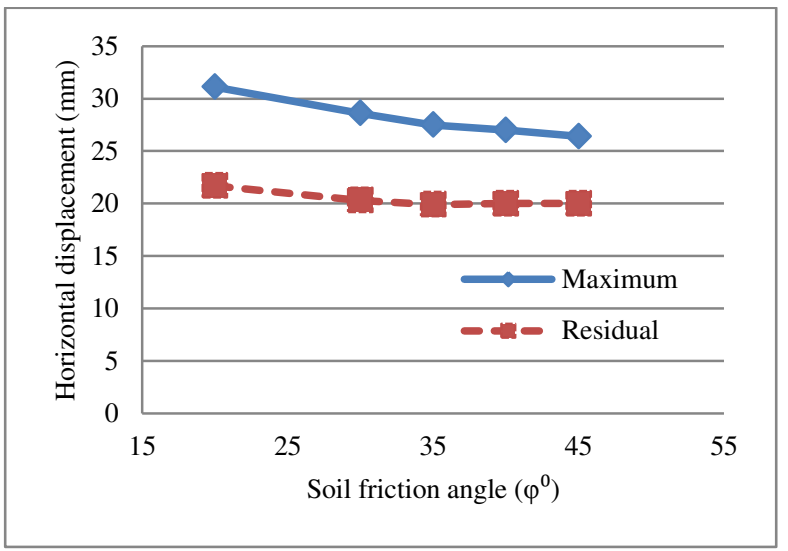

Figure 5. Pile displacements versus soil friction angle

The effect of the soil Poisson's ratio on the pile foundation behavior under blast loadings was studied for different values of soil Poisson's ratio from 0.2 to 0.4 . In this analysis, soil cohesion, friction angle and density were kept constant as $50 \mathrm{kPa}, 40^{\circ}$ and $1960 \mathrm{~kg} / \mathrm{m}^{3}$, respectively. Figure 6 shows that by increasing the soil Poisson's ratio from 0.2 to 0.4 , the maximum pile deflection at the mid-height of the pile decreases by about $8 \mathrm{~mm}$ and also the residual pile deflection at the mid-height of the pile decreases by about $10 \mathrm{~mm}$. These variations indicate that the Poisson's ratio has some effect on the blast response of the pile.

The influence of the soil density on the pile foundation behavior under blast loading was also studied by considering the pile embedded in soils with four different densities of $1250,1500,1750$ and $1960 \mathrm{~kg} / \mathrm{m}^{3}$. Pile deflections at the mid-height of the each pile were obtained for the purpose of comparison. Figure 7 shows the numerical results for maximum and residual pile deflections at its mid-height against soil density. As can be seen, it is clear that both maximum and residual pile deflections decrease significantly as soil density increases. The maximum pile horizontal deflection and residual horizontal deflection decrease by about $60 \%$ and $43 \%$, respectively, by increasing the soil density from 1250 to $1960 \mathrm{~kg} / \mathrm{m}^{3}$. It may therefore be concluded that soil density has a significant effect on the blast response of the pile.

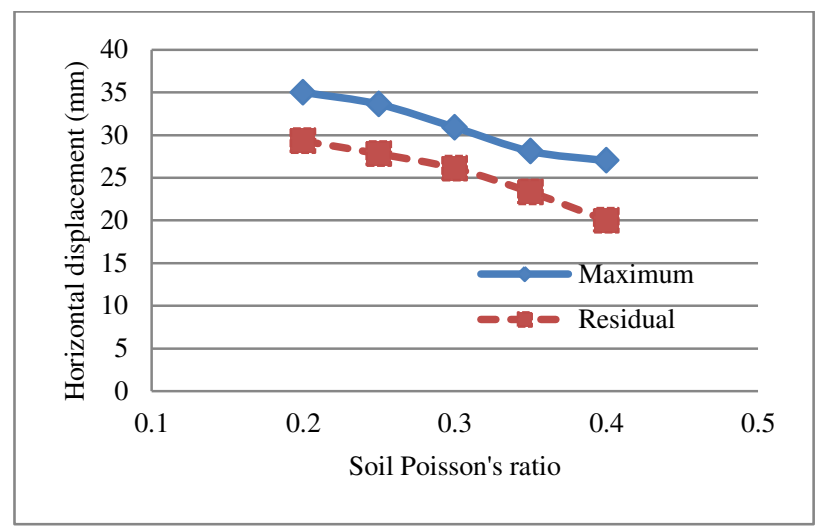

Figure 6. Pile displacements versus soil Poisson's ratio

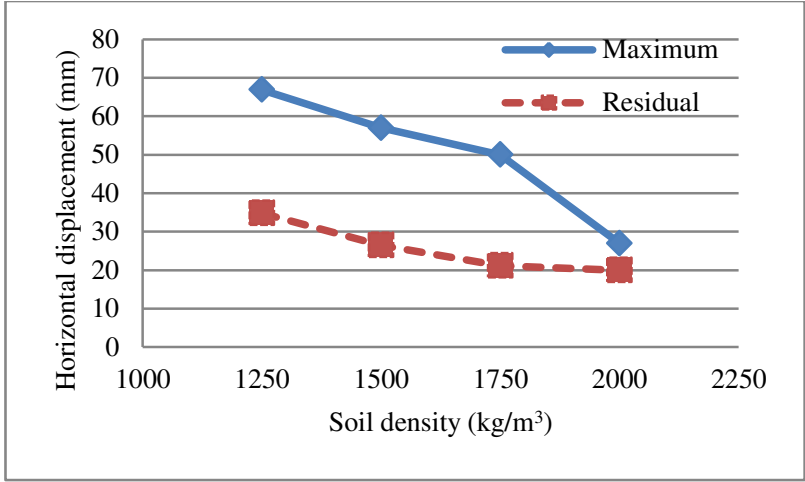

Figure 7. Pile displacements versus soil density

\section{CONCLUSION}

A fully coupled numerical procedure incorporating different material models for the explosive, air, soil and pile (concrete and steel) was developed and applied to study the dynamic response of reinforced concrete pile foundations subjected to surface explosion using the commercial computer program LS-DYNA. The ALE formulation is used in the explosion, air domain and soil region near the explosion to eliminate the distortion of the mesh under high deformation. The modelling techniques used in the present paper have been validated as described in an earlier paper [11]. A series of parametric studies was carried out to study the 
significance and sensitivity of important soil parameters on the blast response of the pile foundation at its mid height. The main outcomes of this study are briefly presented below.

- Density and cohesion of soil have significant influence of the deflection response of the pile under blast loading and are more sensitive than the friction angle and Poisson's ratio.

- Soil density is the most sensitive parameter influencing the blast response of the pile foundation, with about $60 \%$ variation in the maximum horizontal deflection across the range of density values considered.

- Soil cohesion and Poisson's ratio also have some influence on the blast response of the pile with variations in the maximum horizontal deflection of $41 \%$ and $23 \%$ respectively and variations of $40 \%$ and $31 \%$ in the residual horizontal deflections respectively, for the range of these parameters considered.

- Friction angle has the least influence on the pile response to blast loading with a variation of about $15 \%$ across the range of this parameter considered in the study.

- This information will (i) be useful in understanding the blast response of piles embedded in different soils, (ii) expand the current knowledge based in this area and (iii) provide a reference for future analysis and design of pile foundations vulnerable to blast loading.

\section{ACKNOWLEDGMENT}

This material is based on research/work supported by the Land and Liveability National Innovation Challenge under L2 NIC Award No. L2NICCFP1-2013-1.

Any opinions, findings, and conclusions or recommendations expressed in this material are those of the author(s) and do not necessarily reflect the views of the L2 NIC.

\section{REFERENCES}

[1] UFC 3-340-02, Structures to resist the effects of accidental explosions, US Army technical manual, 2014.

[2] Jayasooriya R., Thambiratnam D.P., Perera N.J., and Kosse V., Blast and residual capacity analysis of reinforced concrete framed building, Engineering structures, 2011.

[3] Remennikov A., A review of methods for predicting bomb blast effects on buildings, Journal of Battlefield Technology, 6 (2003), pp 5-10.

[4] AS 2159, Australian Standard: Piling - Design and installation, Standards Australia committee CE-018, 2009.

[5] AS/NZS 1170, Australian/ New Zealand Standard: Structural design actions, Australian and New Zealand standards joint technical committee BD-006, 2002.

[6] AS 3600, Australian Standard: Concrete structures, Standards Australia committee BD-002, 2009.

[7] EN 1991 Eurocode 1, Actions on structures, European committee for standardization, 2006.

[8] Lan S., Crawford J.E., and Morrill K.B., Design of reinforced concrete columns to resist the effects of suitcase bombs, International Proceeding of $6^{\text {th }}$ international conference on shock and impacts loads on structures, Australia, 2005, pp 5-10.
[9] Ngo T., Mendis P., Gupta A., and Ramsay J., Blast loading and blast effects on structures - an overview, EJSE international special issue: Loading on structures, 2007, pp 76-91.

[10] Bao X., and Li B., Residual Strength of Blast Damaged Reinforced Concrete Columns, International Journal of Impact Engineering, 37(3) (2010), pp 295-308.

[11] Jayasinghe L.B., Thambiratnam D.P., Perera N., and Jayasooriya J.H.A.R., Computer simulation of underground blast response of pile in saturated soil, Computers and Structures, 120 (2013), pp 86-95.

[12] Jayasinghe L.B., Thambiratnam D.P., Perera N., and Jayasooriya J.H.A.R., Blast response and failure analysis of pile foundations subjected to surface explosions, Engineering failure analysis, 39 (2014), pp41-54.

[13] Hao H., Pan T.C., and Zhao Z., Inelastic responses of pilesoil system to blast loads, WIT Transactions on the Built Environment, 8 (1994).

[14] Huang B., Gao Q., Wang J., Jiang X., Wang X., Jiang B., and $\mathrm{Wu} \mathrm{W}$., Dynamic analysis of pile-soil-structure interaction system under blasting load, Applied Mechanics and Materials, 638-640 (2014), pp 433-436.

[15] LS-DYNA,Livermore software technology cooperation, LS-DYNA user's manual, version 971, 2007.

[16] Hallquist J.O., LS-DYNA Theoretical Manual - Nonlinear Dynamic Analysis of Structures, Livermore, California: Livermore Software Technology Corporation, Livermore, California, 1998

[17] Lewis B.A., Manual for LS-DYNA soil material mode 147, Federal Highway Administration, FHWA-HRT-04095, McLean, VA, 2004.

[18] Malvar L.J., Crawford J.E., Wesevich J.W., and Simons D.A., A plasticity concrete material model for DYNA3D, International journal of impact engineering, 19 (9-10) (1997), pp 847-873.

[19] Thilakarathna H.M.I., Thambiratnam D.P., Dhanasekar M., and Perara N.J., Numerical Simulation of Axially Loaded Concrete Columns under Transverse Impact and Vulnerability Assessment, International Journal of Impact Engineering, 37(11) (2010), pp1100-1112.

[20] Malvar L.J., Crawford J.E., and Morrill K.B., K and C concrete material model, release III - automated generation of material model input, Karagozian and Case structural engineers, Technical report 2000 TR-99-24.3, 2000.

[21] Tai Y.S., Chu T.L., Hu H.T., and Wu J.Y., Dynamic response of a reinforced concrete slab subjected to air blast load, Theoretical and applied fracture mechanics, 56(2011), pp140-147.

[22] TM5-855-1, Fundamental of protective design for conventional weapons, US Army technical manual, 1986. 